\title{
ENERGY EFFICIENCY PERFORMANCE ENHANCEMENT OF INDUSTRIAL CONVENTIONAL WOOD DRYING KILN BY ADDING FORCED VENTILATION AND WASTE HEAT RECOVERY SYSTEM: A COMPARATIVE STUDY
}

\author{
Yang Meng ${ }^{1}$, Guangyuan Chen ${ }^{2}$, Gonghua Hong ${ }^{1}$, Mingjie Wang ${ }^{1}$, Jianmin Gao ${ }^{1}$, Yao Chen ${ }^{1, \star}$
}

\begin{abstract}
Conventional kilns dominate the wood drying industry. However, energy consumption during the process of ventilation remains a significant challenge. In this study, we designed a device to recover waste heat from exhausted wet air during kiln drying. To determine energy conservation, the device was installed in a $50 \mathrm{~m}^{3}$ kiln used for drying sawn timber in two different Chinese cities, and a traditional kiln with identical size was chosen to enable comparison. Two kinds of hardwood (Betula costata and Quercus mongolica) swan timbers were dried using conventional technology to investigate the energy saving effect of rainy seasons as well as seasonally different temperature. The results revealed that drying time and energy consumption decreased with the use of this energy-conserving device. Electrical and energy consumption were reduced by $18,9 \%$ and $38,5 \%$, respectively. Waste heat recovery efficiencies ranged from $20,32 \%$ to $28,15 \%$. Energy-conservation efficiency can be predicted to range from $12,23 \%$ to $22,74 \%$ annually. Equipment costs can be recovered within 3,5 years.
\end{abstract}

Keywords: Drying, energy conservation, shell and tube exchanger, waste heat, wood.

\section{INTRODUCTION}

Wood processing and timber trade are two important components of modern forestry development. Before using wood as raw materials to make furniture and other products, drying is one of the most fundamental steps in the forest product industry to improve wood properties, which can raise the rate of wood utilizing (Ananías et al. 2012, Korkut et al. 2013, Fu et al. 2016). Conventional kiln drying is the dominating method in sawmilling due to low cost and wide adaptability, consequently drying more than $80 \%$ of all produced lumber in China (Li et al. 2008). However, the relatively high energy consumption during ventilation stagnates development of the technique. It has been reported that energy consumption in lumber drying utilizes $50-70 \%$ of the total energy required for wood processing and manufacturing (He et al. 2016). Most of the energy lost is attributed to traditional ventilation, where hot and wet air is directly exhausted (Figure 1), and fresh air is absorbed into the kiln (Elustondo and Oliveira 2009). This requires heating of the incoming air to reach drying medium temperature (Gu 2007). Designing energy conservation devices for conventional wood kiln drying is a matter of economic urgency (Simo-Tagne et al. 2017).

Waste-heat recovery technology is an efficient tool to reduce energy consumption and is widely used in the food industry (Aktas et al. 2016, Jokiniemi et al. 2016), tobacco industry (Arsenyeva et al. 2016), and con-

${ }^{1} \mathrm{MOE}$, Key Laboratory of Wooden Material Science and Application, College of Material Science and Technology, Beijing Forestry University, Beijing, China.

${ }^{2} \mathrm{MOE}$, Key Laboratory of Bio-based Material Science and Technology, College of Material Science and Engineering, Northeast Forestry University, Harbin, China.

"Corresponding author: ychen@bjfu.edu.cn

Received: 24.06.2017 Accepted: 08.06.2019 
struction industry (Gendebien et al. 2013, O'Connor et al. 2016, Tanczuk et al. 2016). As for wood industry, waste heat recycling in the kilns is also in quite common use especially in Europe and North America (Anderson and Westerlund 2014). In the past three decades, teams of researchers have devoted cumulative efforts to improve the energy efficiency via recovering the waste heat in the discharged moist gas with different heat integration approaches. Up to now, two classes of devices for waste-heat recovery in wood kiln drying have been developed. The first one is retaining traditional ventilation ducts and simply adding heat recovery devices to it, while the second one is developing novel ventilation types. Original research primarily focused on the first type. Dehumidification drying (Zhang et al. 2007) can be seen as early attempt; however, compared to recovering waste heat, its high electric energy inputs outweighed the gain. With the development of heat-pump technology, an increasing number of high-efficiency energy recovery systems including mechanical heat pump system (MHP) and absorption heat pump system (AHP), were applied integrated with the drying processes (Minea 2012, Qiu et al. 2016). Anderson and Westerlund (2014) developed a MHP system coupled with conventional drying kiln in a Swedish sawmill, showing that the heat demand decreased by 5,6 TW h/year. Ye et al. (2015) exploited a novel AHP directly installing the ventilation ducts. The simulation results demonstrated the efficiency of heat recovery varied from $15,1 \%$ to $54,8 \%$. Although heat pump technology can greatly improve energy efficiency, the high cost limits the industrial application, especially in small sawmills. Due to the low investment and easy to install, air/air heat exchanger will be a good solution. In the research of Pazitny et al. (2015), a spiral heat exchanger was applied in the kiln, decreasing the heat consumption by 25000 up to $31000 \mathrm{GJ}$ per year. Laurijssen et al. (2010) introduced a tube-and-shell heat exchanger (TSHE) to conventional dryers to pre-heat the incoming air by recovering heat from the exhaust moist gas, causing $15 \%$ decrease of energy consumption in drying process of forest industry. However, these aforementioned heat exchangers are all directly used in conventional kilns without adding extra fans to overcome the flow resistance, which played an important role in dehumidification rates, leading to an increase in drying cycles, especially for hot gas exiting the kiln with high moisture. Moreover, the traditional ventilation duct types (Figure 1) may always disturb the airflow distribution in the dry kiln when exchanging air. Therefore, developing a novel ventilation type which can not only recover waste heat through heat exchanger with high efficiency, but can also improve the airflow uniformity circulation of drying kilns, is urgently demanded.

Overall, the existing energy conserving devices have hardly been used in industrial conventional wood drying kilns due to their complex structure and comparatively high cost. Furthermore, the lack of technical staffs that are required to handle such devices at kilns is a further obstacle. In this study, a novel energy-conserving device was designed and installed in a $50 \mathrm{~m}^{3}$ wood drying kiln in two different Chinese cities to test the energy efficiency performance in rainy seasons and cold days. Experiments were conducted in real industrial drying production during both hot summer and cold winter. The findings of this study provide a theoretical fundament for the feasibility of applying this novel device. Drying time, energy conserving efficient, and drying cost were investigated and compared with traditional wood kiln drying.
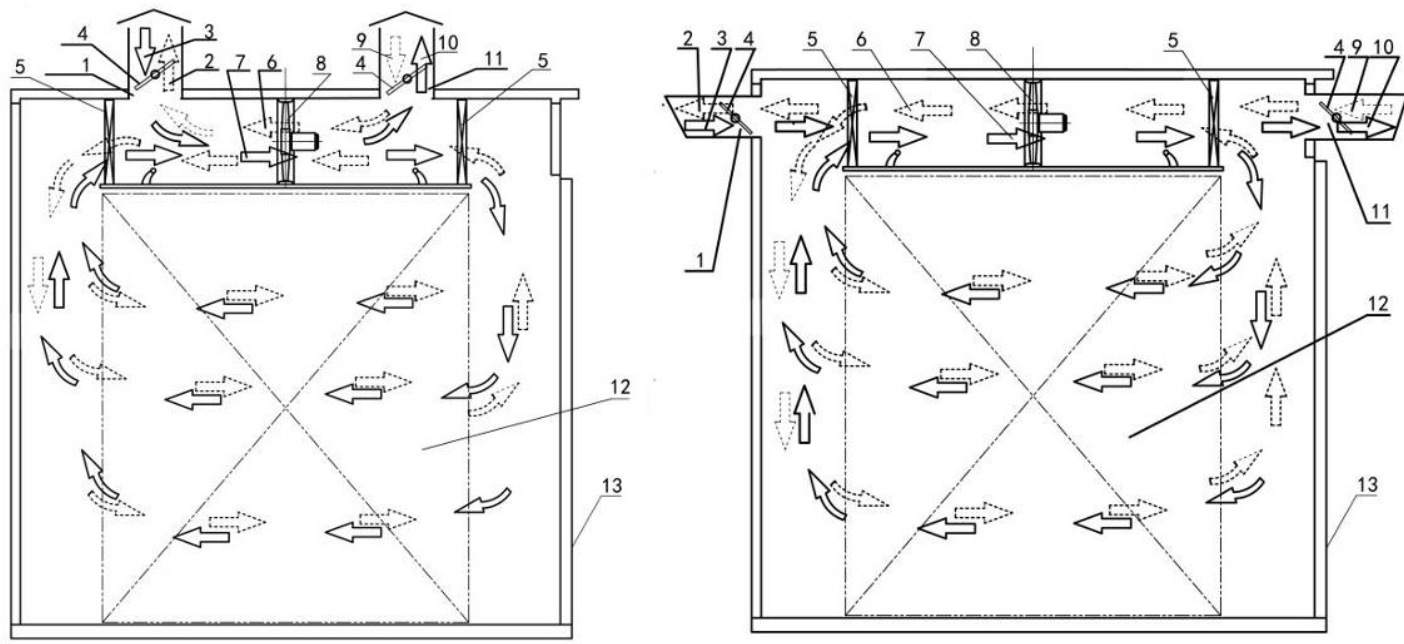

Figure 1: Airflow circulation of conventional drying kiln. 1. Forward (reverse) inlet (outlet) duct; 2 . Reverse exhaust wet air; 3 . Forward fresh air; 4 . Butterfly valve; 5 . Heating coils; 6 . Reverse circulating air; 7. Forward circulating air; 8. Axial fan; 9. Reverse fresh air; 10. Forward exhaust wet air; 11. Reverse (forward) inlet (outlet) duct; 12. Wood stacks; 13. Kiln gate. 


\section{Forced ventilation and waste heat recovery system}

\section{Structure and principle}

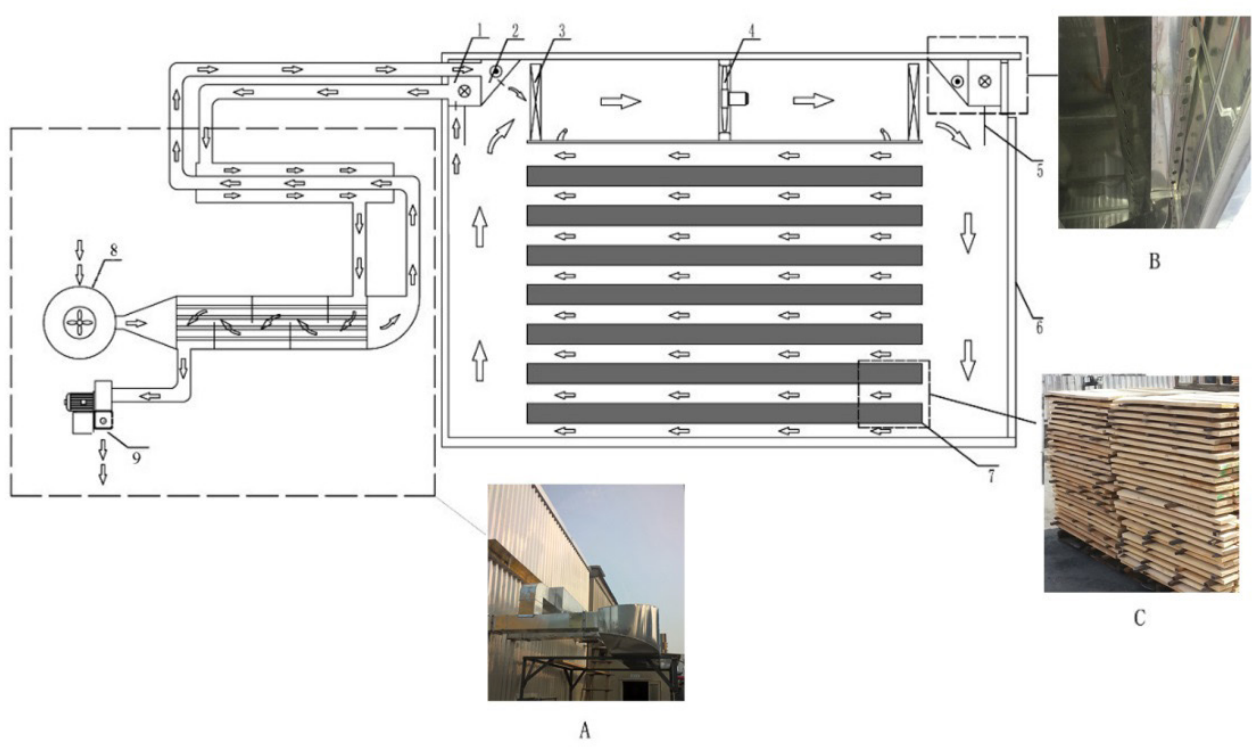

Figure 2: Two-dimensional schematic diagram of novel kiln. 1. Exhaust air duct; 2. Inlet air duct; 3. Heating coils; 4. Axial fan; 5. Wind deflector; 6. Kiln gate; 7. Wood stacks; 8. Intake centrifugal fan; 9. Exhaust centrifugal fan.

A schematic diagram of the device is presented in Figure 2. The ventilation ducts are designed in a novel pattern (Figure 2b), which consists of two groups of geometric hollow pipes hanging on the inner top corner of the kiln. A hollow pipe with trilateral cross section is used as air inlet tube, while the hollow pipe installed close to it is used as air exhaust tube. The orifices arranged in the tube are channels for air inlet and outlet of the kiln. The forced ventilation and waste heat recovery system is shown in Figure 2a. Here, heat recovery takes place when the ventilation fans inject fresh air and hot humid waste air (HHWA) into the system. Fresh air was heated via heat recovered from the HHWA.

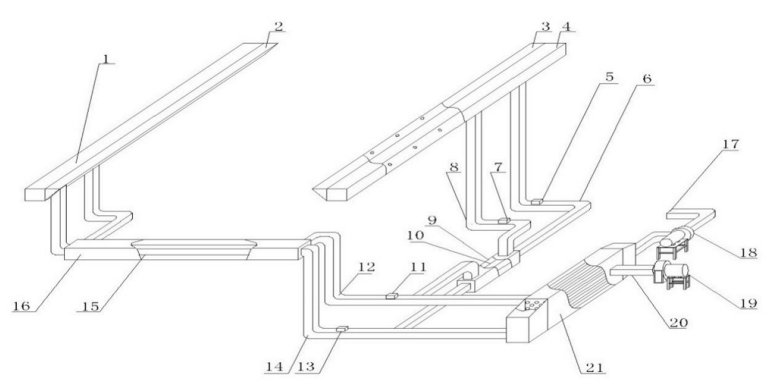

Figure 3: Three-dimensional structure diagram of the energy-conserving device. 1. Reverse exhaust duct; 2. Reverse inlet duct; 3. Forward inlet duct; 4. Forward exhaust duct; 5. Forward inlet pipeline butterfly valve; 6 . Forward inlet pipeline; 7 . Forward exhaust pipeline butterfly valve; 8 . Forward exhaust pipeline; 9. Forward casing pipe shell; 10. Forward casing pipe tube; 11. Reverse exhaust pipeline butterfly valve; 12 . Reverse exhaust pipeline; 13 . Reverse inlet pipeline butterfly valve; 14 . Reverse inlet pipeline; 15 . Reverse casing pipe tube; 16 . Reverse casing pipe shell; 17. Total inlet pipeline; 18. Intake centrifugal fan; 19. Exhaust centrifugal fan; 20. Total exhaust pipeline; 21. Shell and tube heat exchanger. 
A three-dimensional structure diagram of this device is presented in Figure 3. The device consists of an air powered source, heat exchanger, and ventilation pipes. In this study, the parameters of the device were calculated and designed based on a $50 \mathrm{~m}^{3}$-capacity wood kiln.

\section{Air power source}

Ventilation fans with high total pressure were acquired considering linear and local pressure loss when air was transmitted through pipelines and heat exchanger (O'Connor et al. 2016). To this regard, two centrifugal fans with the same parameters were employed as intake fan and exhaust fan (part 18 and 19). The intake fan operating parameter is identical to the exhaust fan to avoid generating positive or negative pressure in the drying kiln. The air volume was taken into account to match air exchange rates of the wood kiln. The parameters of the centrifugal fans in a $50 \mathrm{~m}^{3}$ kiln are presented in Table 1 .

Table 1: Parameters of the centrifugal fan.

\begin{tabular}{|c|c|}
\hline Operating Parameters & Values \\
\hline Rated Voltage $(\mathrm{V})$ & 220 \\
\hline Power Rating $(\mathrm{kW})$ & 1,5 \\
\hline Rated Frequency $(\mathrm{Hz})$ & 50 \\
\hline Total Pressure $(\mathrm{Pa})$ & $900-1200$ \\
\hline Volume Flowrate $\left(\mathrm{m}^{3} \cdot \mathrm{h}^{-1}\right)$ & $2000-2500$ \\
\hline
\end{tabular}

\section{Heat exchanger}

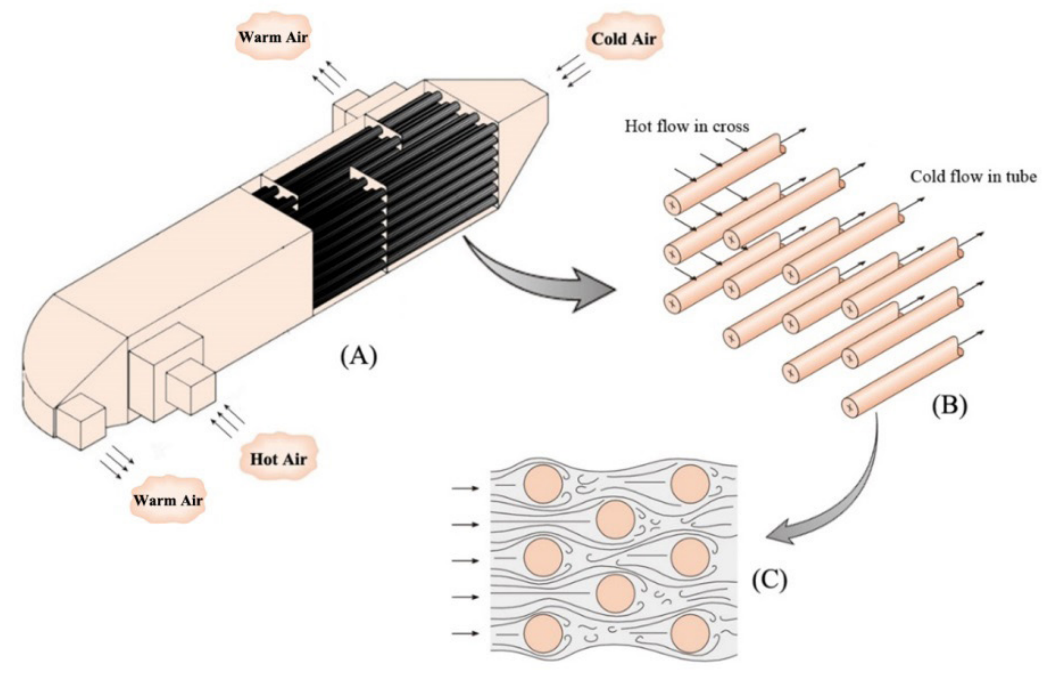

Figure 4: Principle and structure of heat exchanger. (a) shell and tube heat exchanger; (b) flow pattern of the heat exchanger; (c) staggered arrangement of the tubes.

A shell and tube heat exchanger made of aluminum alloy (thickness of $3 \mathrm{~mm}$, roughness of $0,01 \mathrm{~mm}$ ) was utilized in this device. The principle and structure of the heat exchanger are present in Figure 4. A shell and tube heat exchanger is a typical form that is a popular application in industry due to its simple structure, low cost, and comparatively increased heat-transfer efficiency (Tehrani et al. 2016). A single tube and shell pass was employed as the heat exchanger (Figure 4a). To enhance heat transfer efficiency, hot and cold air enter at 
opposite ends of the heat exchanger (Ozden and Tari 2010), i.e. cold air flows inside the tubes in one direction, while hot air flows perpendicularly outside the tubes (Figure 4b). The arrangement form of the tubes is an important factor correlating with turbulent intensity. A staggered arrangement was utilized as it provides considerable tortuous flow across the tubes (Figure 4c). The heat exchange efficiency was increased, particularly due to small Reynolds numbers. Baffles with rectangular shape were installed to increase the convection coefficient of the shell passes by inducing turbulence and a cross-flow velocity of the hot air outside the tubes (Ambekar et al. 2016). The parameters of the heat exchanger designed for a $50 \mathrm{~m}^{3}$ wood drying kiln are provided in Table 2 .

Table 2: Design parameters of the shell and tube heat exchanger.

\begin{tabular}{|c|c|c|c|}
\hline \multicolumn{2}{|c|}{ Shell Pass } & \multicolumn{2}{c|}{ Tube Pass } \\
\hline Parameters & $\begin{array}{c}\text { Data or } \\
\text { description }\end{array}$ & Parameters & $\begin{array}{c}\text { Data or } \\
\text { description }\end{array}$ \\
\hline Section Shape & Rectangle & Section Shape & Circular \\
\hline Length (m) & 4,6 & Staggered Pattern & Regular triangle \\
\hline Width (m) & 0,6 & Diameter (m) & 0,06 \\
\hline Height (m) & 0,6 & Length (m) & 3,0 \\
\hline Quantity (EA) & 1 & Quantity (EA) & 60 \\
\hline
\end{tabular}

\section{Ventilation pipes}

The structure of the ventilation pipes is shown in Figure 3 (part 1-4). The intake pipes with right-angled triangle section shape (dimensions: 4,6 m long, 0,4 m wide, $0,5 \mathrm{~m}$ high) and the exhausted pipes with rectangle section shape (dimensions: 4,6 m long, $0,5 \mathrm{~m}$ wide, $0,5 \mathrm{~m}$ high) were designed according to the kiln inner space and ventilation volume. The total area of the orifices in the inlet or outlet of ventilation pipes should be less than half of the cross section of ventilation pipes. Considering the importance of outflow uniformity on the circulation velocity in the drying kiln, the orifice radius was calculated via Equation 1 (Yang et al. 2011):

$$
r_{i}=\sqrt{\frac{\bar{m}}{\dot{m}_{i}} r}
$$

Where $\dot{m}_{i}$ is the ventilation rate $\left(\mathrm{m}^{3} \mathrm{~h}^{-1}\right)$ of orifices $(\mathrm{i}=1,2, \ldots \ldots, 30), \bar{m}$ is the average ventilation rate $\left(\mathrm{m}^{3} \mathrm{~h}^{-1}\right), r$ is the theoretical orifice radius $(\mathrm{m})$, and $r_{i}$ is the rational orifice radius $(\mathrm{m})$. The main parameters of the designed ventilation pipes are presented in Table 3.

Table 3: Main design parameters of ventilation pipes.

\begin{tabular}{|c|c|c|}
\hline Parameters & $\begin{array}{c}\text { Data or regression } \\
\text { formula }\end{array}$ & $\begin{array}{c}\text { Reference } \\
\text { data }\end{array}$ \\
\hline First inlet orifice radius $(\mathrm{m})$ & 0,05 & Calculated \\
\hline Inlet orifice radius $(2,3, \ldots \ldots)$ & $\begin{array}{c}\mathrm{y}=0,11 \mathrm{x}- \\
2+0,88 \mathrm{x}+34,033\end{array}$ & $\begin{array}{c}\text { Yang } \text { et } \\
\text { al. }(2011)\end{array}$ \\
\hline First outlet orifice radius $(\mathrm{m})$ & 0,06 & Calculated \\
\hline Outlet orifice radius $(2,3, \ldots \ldots)$ & $\begin{array}{c}\mathrm{y}=-0,015 \mathrm{x} 2- \\
0,484 \mathrm{x}+45,506\end{array}$ & $\begin{array}{c}\text { Yang } \text { et al. } \\
(2011)\end{array}$ \\
\hline Total inlet orifice quantity & 30 & Calculated \\
\hline Total outlet orifice quantity & 30 & Calculated \\
\hline
\end{tabular}




\section{MATERIALS AND METHODS}

To evaluate the influence of rainy seasons and seasonal differences in temperature on the energy-saving effect of the designed device, this study was conducted in Benxi $\left(40^{\circ} 49 \mathrm{~N} 123^{\circ} 34^{\prime} \mathrm{E}\right)$ and Suifenhe $\left(44^{\circ} 38^{\prime} \mathrm{N} 131^{\circ} 17^{\prime} \mathrm{E}\right)$. Experimental kilns with the designed devices were established in both districts, and a traditional kiln with identical size was chosen to enable comparison (named control kiln). The inner size of all kilns was $4600 \mathrm{~mm}$ (length) x $8600 \mathrm{~mm}$ (width) x $6000 \mathrm{~mm}$ (height) and the capacity of timber stacks was 50 $\mathrm{m}^{3}$. Betula costata Trautv obtained from Russia with dimensions of $1000 \mathrm{~mm}$ (lengths) x $150 \mathrm{~mm}$ (width) x 35 $\mathrm{mm}$ (height), average initial moisture content of $40 \%$, and basic density of $450 \mathrm{~kg} / \mathrm{m}^{3}$, was dried in Suifenhe; Quercus mongolica obtained from the Changbai Mountains in northeastern China with dimensions of $900 \mathrm{~mm}$ (lengths) x $100 \mathrm{~mm}$ (width) $35 \mathrm{~mm}$ (height), average initial moisture content of $43 \%$ in summer and $50 \%$ in winter, and a basic density $650 \mathrm{~kg} / \mathrm{m}^{3}$, was chosen as the experiment timber in Benxi. The drying schedule of Betula costata Trautv was fluctuating from $50{ }^{\circ} \mathrm{C}$ to $56{ }^{\circ} \mathrm{C}$ (dry bulb). The drying schedule of Quercus mongolica is presented in Table 4 .

Table 4: Drying schedule of Quercus mongolica.

\begin{tabular}{|c|c|c|c|}
\hline $\begin{array}{c}\text { Moisture } \\
\text { Content }(\mathbf{\%})\end{array}$ & $\begin{array}{c}\text { Dry Bulb } \\
\text { Temperature }\left({ }^{\mathbf{}} \mathbf{C}\right)\end{array}$ & $\begin{array}{c}\text { Wet Bulb } \\
\text { Temperature }\left({ }^{\mathbf{O}} \mathbf{C}\right)\end{array}$ & $\begin{array}{c}\text { Equilibrium } \\
\text { Moisture content (\%) }\end{array}$ \\
\hline MC>40 & 45 & 43 & 18,5 \\
\hline $40 \sim 35$ & 48 & 45 & 16,3 \\
\hline $35 \sim 30$ & 50 & 47 & 16,0 \\
\hline $30 \sim 25$ & 52 & 49 & 15,8 \\
\hline $25 \sim 20$ & 54 & 49 & 13,0 \\
\hline $20 \sim 15$ & 56 & 49 & 10,5 \\
\hline $15 \sim 10$ & 58 & 47 & 9,5 \\
\hline $10 \sim 8$ & 60 & 45 & 6,5 \\
\hline
\end{tabular}

To gain the energy saving effect of rainy seasons, the experiment was conducted in Suifenhe with high relative humidity $(\mathrm{RH})$. Compared to traditional ventilation, the fresh air obtained from the inner control room had a lower RH, which may decrease the drying or ventilation time during the rainy season. An electric meter (DTS634, 220V, 30 100A, made in China) and steam flowmeter (YD-LUGB, 25DN, made in China) were utilized to record energy consumption. During drying, the moisture content of the timber was tested and calculated via the weighing method once per day. The over-dry weight of the tested pieces was obtained after drying in an oven at $103 \pm 2{ }^{\circ} \mathrm{C}$. The moisture content (MC) was calculated according to Equation 2 (Zhao et al. 2016):

$$
M C=\frac{M_{t i m e l y}-M_{o v e r-d r y}}{M_{o v e r-d r y}} \times 100 \%
$$

Where $M_{\text {timely }}$ is the timely weight (g) and $M_{\text {over-dry }}$ is the over-dry weight (g).

To obtain the energy saving performances of seasonally different temperature, the experiment was conducted in cold winter and hot summer. Before drying, small holes were drilled in the middle of the intake and exhaust ducts near the inlet and outlet, which were used to test temperature and relative humidity. The temperature was measured with a PT100 temperature sensor (accuracy of $0,1{ }^{\circ} \mathrm{C}$, error $0,5{ }^{\circ} \mathrm{C}$ ) in the hole and recorded via temperature detection apparatus (Yaoyi, XMT-16, made in China) connected to a computer. The relative humidity was measured via portable hygrometer (Rotronic, scale $0-100 \%$, accuracy $0,02 \%$, error $\pm 0,8 \%$, made in Switzerland). The inverter (Invt, CHF100A, made in China) was employed in the experimental kiln to adjust circulation velocity as airflow in wood stack, which slightly influenced the drying rate (Wallace and Avramidis 2016, Zadin et al. 2015).

During drying, the temperature and relative humidity of every drying schedule was recorded to calculate the heat quantity, which was calculated as Equation 3: 


$$
Q=M \times H
$$

Where $Q$ is the total heat content $(\mathrm{kJ}), M$ is the quality of air mixture $(\mathrm{kg})$, and $H$ is the enthalpy $\left(\mathrm{kJ}^{\circ} \mathrm{kg}^{-1}\right)$.

The heat consumption in the control kiln without energy-conserving device was obtained based on drying schedule and Equation 3. The fresh air physical parameters are listed in Table 5.

Table 5: Fresh air physical parameters.

\begin{tabular}{|c|c|c|c|c|c|c|}
\hline \multirow{2}{*}{ Mouth } & \multicolumn{3}{|c|}{ Fresh air outside kiln } & \multicolumn{3}{c|}{ Fresh air inner control room } \\
\cline { 2 - 7 } & $\begin{array}{c}\mathbf{T} \\
\left({ }^{\circ} \mathbf{C}\right)\end{array}$ & $\begin{array}{c}\mathbf{R H} \\
\mathbf{( \% )}\end{array}$ & $\begin{array}{c}\mathbf{H} \\
\left(\mathbf{k J}^{\mathbf{\%}} \mathbf{- 1}\right)\end{array}$ & $\begin{array}{c}\mathbf{T} \\
\left({ }^{\mathbf{O}} \mathbf{C}\right)\end{array}$ & $\begin{array}{c}\mathbf{R H} \\
\mathbf{( \% )}\end{array}$ & $\begin{array}{c}\mathbf{H} \\
\left(\mathbf{k J} \mathbf{k g}^{-\mathbf{1}}\right)\end{array}$ \\
\hline Winter & -11 & 65 & $-8,71$ & 30 & 30 & 50,65 \\
\hline Summer & 25 & 75 & 63,64 & 30 & 30 & 50,65 \\
\hline
\end{tabular}

$\mathrm{T}$, dry bulb temperature; $\mathrm{RH}$, relative humidity; $\mathrm{H}$, enthalpy.

Heat recovery efficiency represented the capacity for the device to recycle waste heat, which was calculated as Equation 4:

$$
\eta=\frac{Q_{\mathrm{r}}}{Q_{c}} \times 100 \%
$$
$(\mathrm{kJ})$.

where $Q_{\mathrm{r}}$ is the recycled energy utilized to heat fresh air $(\mathrm{kJ})$ and $Q_{\mathrm{c}}$ is the energy reduced via this device

Energy-conservation efficiency was used to evaluate the energy saving effect, which was calculated as Equation 5:

$$
\xi=\frac{Q_{C}-Q_{E}}{Q_{C}} \times 100 \%
$$

where $Q_{\mathrm{C}}$ and $Q_{\mathrm{E}}$ are the energy to heat fresh air with the heating system in control and experimental kiln $(\mathrm{kJ})$, respectively.

\section{RESULTS AND DISCUSSION}

\section{Energy saving effect of rainy seasons}

\section{Drying curve history}

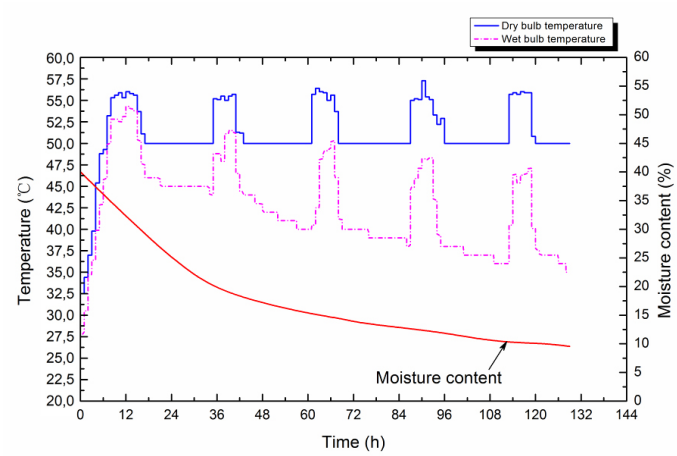

Figure 5: Variation of dry-medium temperature and timber MC in experimental kiln. 


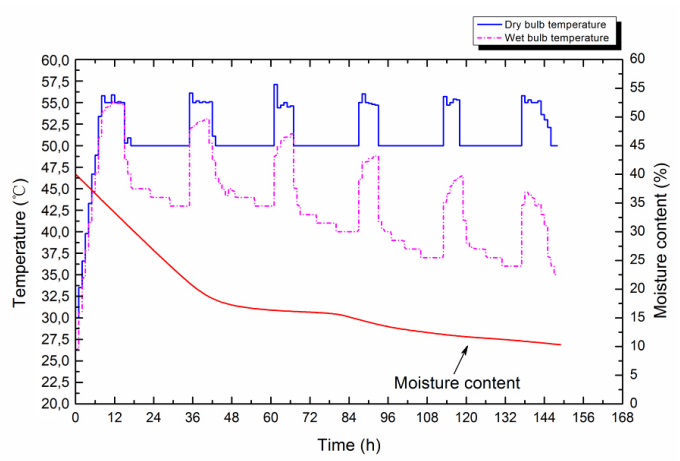

Figure 6: Variation of dry-medium temperature and timber MC in control kiln.

The variation of timber MC and dry-wet bulb temperature of drying medium in experimental and control kiln are shown in Figure 5 and Figure 6, respectively. The average initial MC of the timber was $40 \%$. It took $149 \mathrm{~h}$ and $129 \mathrm{~h}$ to reach the aimed final MC of $10 \%$ for control and experimental kiln, respectively. The drywet bulb temperature curves reveal that the drying process was fluctuant drying. At pretreatment stage, the drying medium was heated to $56^{\circ} \mathrm{C}$, which was retained for $8 \mathrm{~h}$. of the drying medium increased when water was evaporating from timbers. During the drying process, the dry bulb temperature fluctuated from $50{ }^{\circ} \mathrm{C}$ (retained for $20 \mathrm{~h}$ ) to $56^{\circ} \mathrm{C}$ (retained for $6 \mathrm{~h}$ ) with ventilation ducts turned on and off, respectively. The temperature of drying medium in the control kiln fluctuated five times, while it fluctuated four times in the experimental kiln. The fresh air obtained from within the room had lower moisture and higher temperature than the air from outside the kiln and the experimental kiln required less fresh air to decrease the RH of the dry medium. Therefore, the $\mathrm{MC}$ of the timbers in the experimental kiln decreased quickly and almost in line in the middle and late drying period compared to the control kiln, where the $\mathrm{MC}$ of the timbers decreased slowly especially during the drying period (40-76 h). Furthermore, the drying time of the experimental kiln was also reduced by $20 \mathrm{~h}$ compared to the control kiln.

\section{Energy saving effect}

Electricity and steam consumptions of the control and experimental kilns in a drying period are presented in Figure 7. The electricity consumption of the control kiln and experimental kiln are $1211 \mathrm{kWh}$ and 982 $\mathrm{kw}$, respectively. Although extra electricity consumption was needed due to ventilation fans, the electricity consumed by the experimental kiln was still reduced by $229 \mathrm{kwh}$, resulting in an electricity-conserving rate of $18,9 \% 15337 \mathrm{~kg}$ and $9430 \mathrm{~kg}$ of steam with a pressure of $0,4 \mathrm{MPa}$ were consumed by the control kiln and experimental kiln, respectively. The steam consumption decreased due to fewer ventilation times, lower RH, and higher temperature of fresh air in the experimental kiln. The steam-conserving rate was $38,5 \%$. The kiln with energy-conserving devices decreased drying time and energy consumption, especially for rainy days.

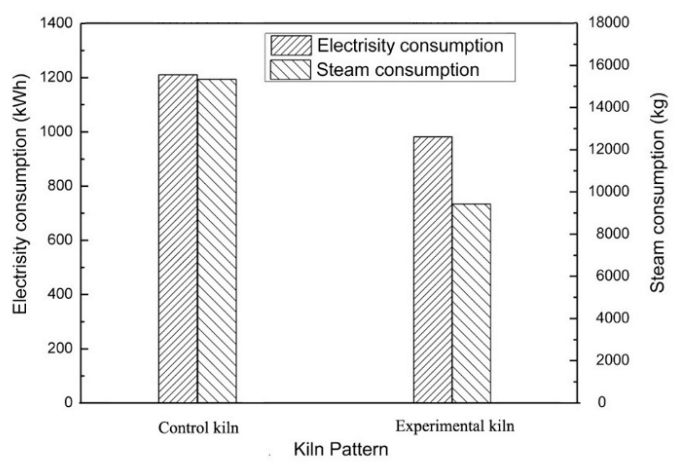

Figure 7: Statistics of electricity and steam consumptions. 


\section{Energy saving effect of seasonally different temperature}

\section{Variation of the properties of fresh and exhausted air in different drying stages}

According to the drying schedule presented in Table 4, the drying process was divided into eight drying stages. The properties of wet and hot air exhausted from the control kiln during different drying stages are presented in Table 6 . Table 7 provides the physical parameters of fresh air from the outlet of the tube pass and wet heat air from the outlet of the shell pass in the experimental kiln.

Table 6: Properties of wet and hot air exhausted from control kiln.

\begin{tabular}{|c|c|c|c|c|}
\hline Drying stage & $\mathrm{T}\left({ }^{\circ} \mathrm{C}\right)$ & RH (\%) & H $\left(\mathbf{k J} \cdot \mathrm{kg}^{-1}\right)$ & $\mathrm{T}_{\mathrm{d}}\left({ }^{\circ} \mathrm{C}\right)$ \\
\hline 1 & 44,0 & 88,9 & 185,15 & 41,95 \\
\hline 2 & 47,0 & 84,2 & 204,63 & 43,85 \\
\hline 3 & 49,0 & 84,5 & 226,24 & 45,88 \\
\hline 4 & 51,0 & 84,9 & 250,19 & 47,94 \\
\hline 5 & 53,0 & 76,2 & 250,01 & 47,74 \\
\hline 6 & 55,0 & 68,5 & 249,86 & 47,54 \\
\hline 7 & 56,8 & 54,8 & 225,58 & 44,84 \\
\hline 8 & 58,8 & 43,5 & 203,69 & 42,00 \\
\hline
\end{tabular}

$\mathrm{T}_{\mathrm{d}:}$ dew-point temperature.

Table 7: Physical parameters of fresh air and wet air in experimental kiln.

\begin{tabular}{|c|c|c|c|c|c|c|}
\hline \multirow[b]{2}{*}{$\begin{array}{c}\text { Drying } \\
\text { stage }\end{array}$} & \multicolumn{3}{|c|}{ Outlet of Tube Pass } & \multicolumn{3}{|c|}{ Outlet of Shell Pass } \\
\hline & $\mathrm{T}\left({ }^{\circ} \mathrm{C}\right)$ & $\begin{array}{l}\text { RH } \\
(\%)\end{array}$ & H $\left(\mathrm{kJ} \cdot \mathrm{kg}^{-1}\right)$ & $\mathrm{T}\left({ }^{\circ} \mathrm{C}\right)$ & $\begin{array}{l}\text { RH } \\
(\%)\end{array}$ & H $\left(\mathrm{kJ} \cdot \mathrm{kg}^{-1}\right)$ \\
\hline 1 & 39,5 & 17,8 & 60,45 & 40,0 & 100 & 167,66 \\
\hline 2 & 40,7 & 16,7 & 61,67 & 41,8 & 100 & 183,50 \\
\hline 3 & 42,3 & 15,3 & 63,24 & 43,6 & 100 & 200,87 \\
\hline 4 & 43,1 & 14,7 & 64,10 & 45,4 & 100 & 219,86 \\
\hline 5 & 44,9 & 13,4 & 65,95 & 44,9 & 100 & 214,40 \\
\hline 6 & 46 & 12,6 & 66,97 & 44,5 & 100 & 210,15 \\
\hline 7 & 47,2 & 11,9 & 68,27 & 40,0 & 100 & 167,66 \\
\hline 8 & 48,8 & 11,0 & 69,64 & 38,0 & 100 & 151,58 \\
\hline
\end{tabular}

Figure 8 shows the temperature distribution of the waste heat recovery system during different drying stage by Fluent software (Fluent 6.3, Fluent Inc., USA ). When the wet and hot air entered into the device, the heat exchange took place both in double-pipe heat exchanger (DPHE) and array-tubular heat exchanger (ATHE). As the contact area and fluid path were enhanced with the vertical tubes and parallel baffles, massive waste heat was transferred to the fresh air in ATHE. Compared with drying stage 2, the wet and hot air in drying stage 6 had more energy content. When the high energy density waste air entered into the ATHE, the heat exchange area was broadened and intensively heat transfer caused by high temperature difference formed, so that the fresh air could absorb more waste heat with high temperature, which was in accordance with the test results. 


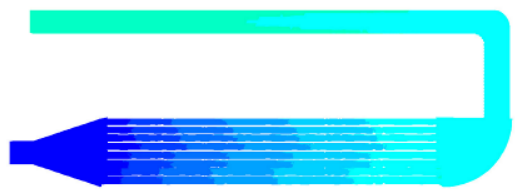

(a)

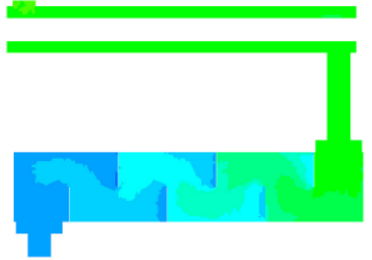

(b)

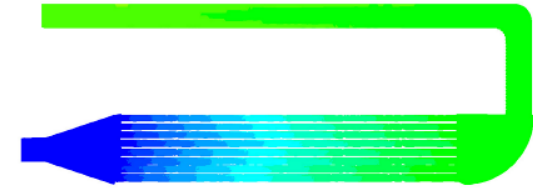

(c)

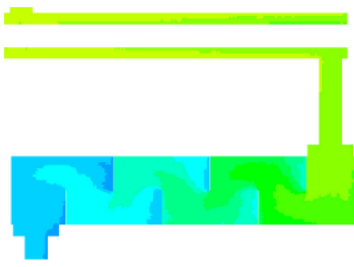

(d)

Figure 8: The temperature distribution of the waste heat recovery system during different drying stage by Fluent software. Temperature distribution of tube pass (a) and shell pass (b) in drying stage 2; Temperature distribution of tube pass (c) and shell pass (d) in drying stage 6.

\section{Statistics and analysis of energy consumption}

The energy consumption is calculated based on Table 5 and Equation 3, and the results are presented in Figure 9 and Figure 10. Figure 9a shows the statistics of energy consumption of different drying stages during a hot summer. It can be seen that, the energy consumption of the experimental kiln $\left(Q_{E 1}\right)$ was lower compared to that of the control kiln $\left(\mathrm{Q}_{\mathrm{Cl}}\right)$ for all stages of the drying process. In summer, the energy consumption was lower in drying stages 1 and 8 . This was attributed to the lower MC of the timbers in those stages. There was no significant difference in energy consumption during drying stages 2-7, since the MC of the timbers in those stages were identical. Figure $9 \mathrm{~b}$ shows the energy consumption performance during the cold winter. In addition to the high energy consumption in the first drying stage, due to the high initial moisture content (50\%), the variation of energy consumption $\left(\mathrm{Q}_{\mathrm{Cl}}, \mathrm{Q}_{\mathrm{C} 2}, \mathrm{Q}_{\mathrm{E} 1}\right.$, and $\left.\mathrm{Q}_{\mathrm{E} 2}\right)$ was similar to the value during summer. Please note that the external environment did not affect the experimental kiln. The variation of energy consumption of the experimental kilns during a hot summer was the same as that during a cold winter.
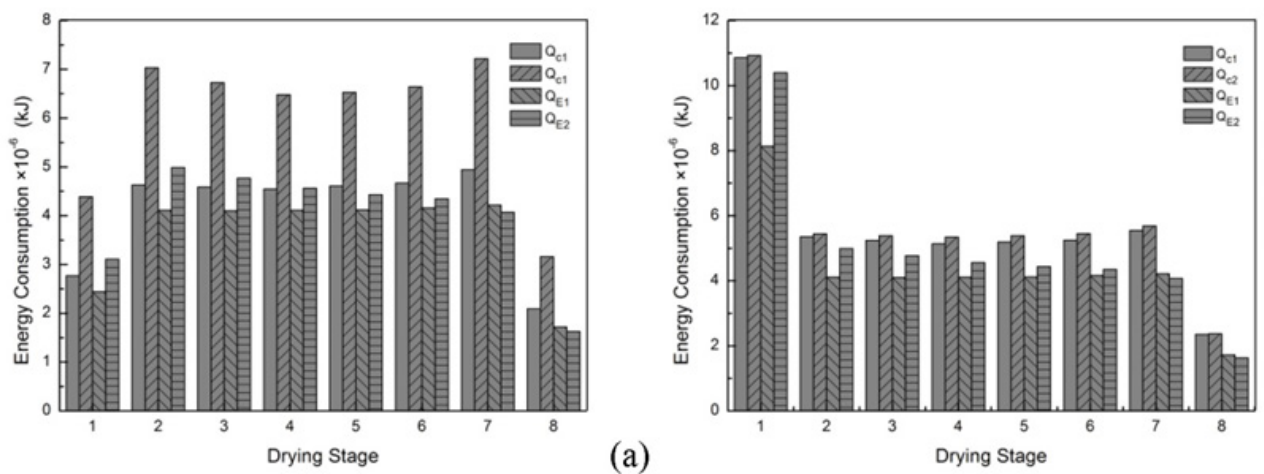

(b)

Figure 9: Energy consumption of different drying stages during summer (a) and during winter (b). $\mathrm{Q}_{\mathrm{C} 1}$ and $\mathrm{Q}_{\mathrm{E} 1}$ represent the energy consumption of the control and the experimental kiln, respectively. $\mathrm{Q}_{\mathrm{C} 2}$ and $\mathrm{Q}_{\mathrm{E} 2}$ represent the energy carried by wet, hot air exhausted from the control and the experimental kiln, respectively. 
Figure 10 presents the variations of energy consumption of the control kiln during the hot summer and cold winter. It was obvious that $\mathrm{Q}_{\mathrm{C} 2}$ (drying stages 2-7) during summer was higher than during winter. Fresh air in summer often carried more moisture than in winter and a large volume of air was required to meet the air exchange rate. As a result, the exhausted wet air in summer is enormous. This contributed to a higher $\mathrm{Q}_{\mathrm{C} 2}$ during summer. Although it needed less fresh air during a cold winter, more energy was required to heat the cold air. In that case, $Q_{C 1}$ in winter was higher than in summer. For the experimental kiln however, both $Q_{E 1}$ and $\mathrm{Q}_{\mathrm{E} 2}$ in summer (Figure 9a) and winter (Figure 9b) were relatively low. Energy consumption sharply decreased by using the energy-conserving device.

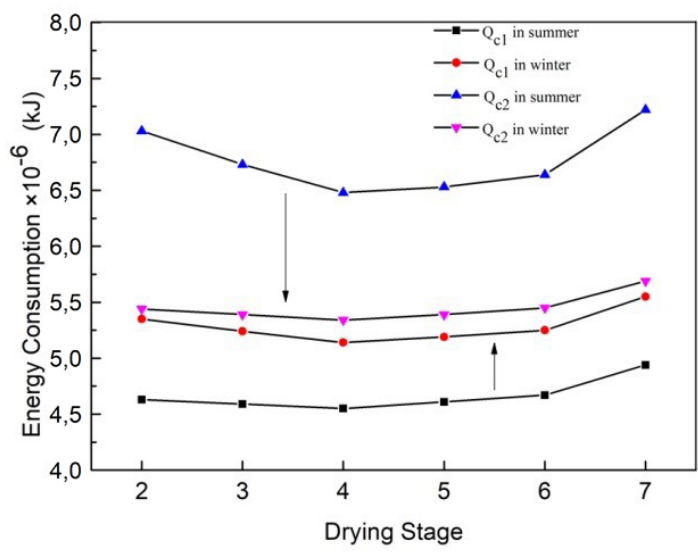

Figure 10: Variations of energy consumption of control kiln during hot summer and cold winter.

\section{Waste heat recovery efficiency}

Figure 11 depicts the waste heat recovery efficiency for different drying stages. During the drying process, the waste heat recovery efficiency is constantly decreasing except for drying stage 8 . The reason may be correlated with thermal loss of the device shell. As the temperature of wet exhausted air increases, accompanied by further drying, the temperature gap between inner device and control room is extended, which can lead to severe energy loss. Although thermal loss varies throughout the different drying stages, waste heat recovery efficiencies are all above $20 \%$, ranging from $20,32 \%$ to $28,15 \%$. Considering that the initial moisture content of lumber changes according to season, the weighted mean of waste heat recovery efficiency was calculated, resulting in $21,54 \%$ for summer and $24,13 \%$ for winter, and it decreased with increasing initial moisture content.

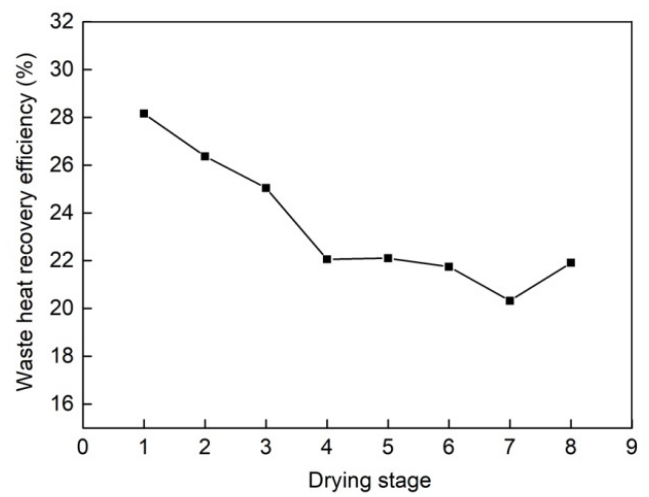

Figure 11: Waste heat recovery efficiency of different drying stages. 


\section{Energy conservation efficiency}

Compared to the energy-conservation efficiency based on the control and the experimental kilns, the values of the energy-conservation efficiency in winter and summer are depicted in Figure 12. The energy-conservation efficiency in winter was higher (ranging from 19,98\% to 26,54\%) than that in summer (ranging from $9,66 \%$ to $17,50 \%)$. The energy-conservation efficiency curve for winter followed the same trend than that for summer, which first decreases, followed by an increase with a minimum value appearing during drying stage 4 , and a maximum value during drying stage 8 . The weighted mean of energy-conservation efficiency in winter and summer was $22,74 \%$ and $12,23 \%$, respectively. In conclusion, it can be predicted that the energy-conservation efficiency for a whole year can be expected to range from $12,23 \%$ to $22,74 \%$.

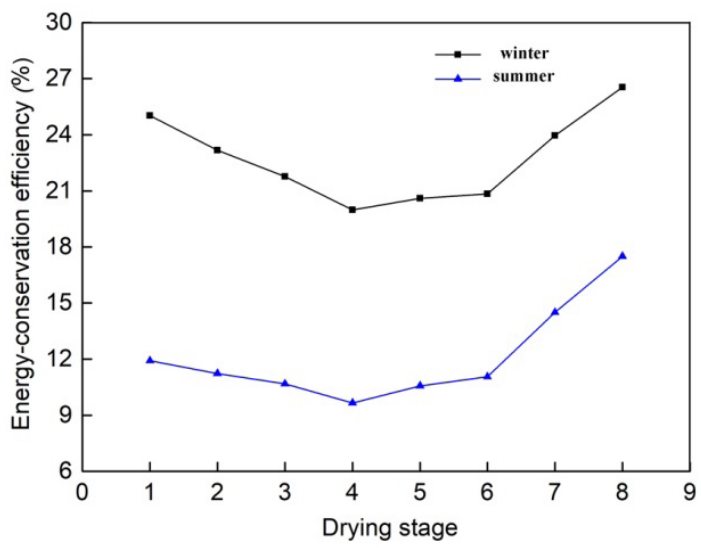

Figure 12: Energy-conservation efficiency of different drying stages.

\section{Economic analysis}

This economic analysis was based on the actual production status in Benxi. The drying period of Quercus mongolica in the experimental kiln was normally 12 to 14 days, which was in line with the initial moisture content (40-50\%). Considering the loss of drying time, due to equipment malfunction, electric blackout, loading, and unloading of drying kilns, the experimental kiln can be approximately operated 25 times per year. The energy conservation and additional electrical power consumption were evaluated and are shown in Table 8 . The experimental kiln, running 25 times a year can save US\$ 446,29 via this energy-conserving device.

Table 8: Energy conservation and additional electrical power consumption.

\begin{tabular}{|c|c|c|c|}
\hline \multicolumn{2}{|c|}{ Energy Conservation } & \multicolumn{2}{c|}{$\begin{array}{c}\text { Additional Electrical Power } \\
\text { Consumption }\end{array}$} \\
\hline Unit savings (t) & 0,24 & $\begin{array}{c}\text { Total running time } \\
(\mathrm{h})\end{array}$ & 1875 \\
\hline Total savings $(\mathrm{t})$ & 6 & Power Usage $(\mathrm{kWh})$ & 5625 \\
\hline Total price & US\$1031,85 & Total price & US\$585,56 \\
\hline
\end{tabular}

Note: Additional electrical power consumption consists of the cost of ventilation fans and its running time is calculated based on average initial moisture contents and ventilation rates. Amounts of energy saving are converted into standard coal. The cost of standard coal is US\$171,98 (including transportation expenses of US\$71,98) per ton. The price of electricity is US $\$ 0,1$ per $\mathrm{kWh}$. 


\section{CONCLUSIONS}

A device with ventilation fans, shell and tube heat exchanger, and ventilation ducts was designed to recover waste heat from exhausted wet air for a wood-drying kiln. The experimental device altered the traditional ventilation mode. The novel mode exchanges air via centrifugal fans and recovers waste heat in a shell and tube exchanger, simultaneously. The experimental kiln reduced electrical energy by $18,9 \%$ and energy consumption by $38,5 \%$. The kiln with energy-conserving devices decreased drying time and energy consumption particularly during the rainy season. The device can recover waste heat efficiently to heat fresh air both during hot summers and cold winters. During the whole drying stage, the waste heat recovery efficiencies ranged from $20,32 \%$ to $28,15 \%$ and weighted mean efficiencies were $21,54 \%$ in summer and $24,13 \%$ in winter. The waste heat recovery efficiencies decreased with increasing initial moisture content of timbers. The energy-efficiency in winter was higher (ranging from $19,98 \%$ to $26,54 \%$ ) compared to that in summer $(9,66 \%$ to $17,50 \%)$. The weighted means of energy-efficiency during winter and summer were $22,74 \%$ and $12,23 \%$, respectively. An economic analysis revealed that the experimental kiln running 25 times per year could save US\$446,29 using the energy-conserving device. Equipment costs can be recovered within 3,5 years via the saving of drying consumption.

\section{ACKNOWLEDGMENTS}

The study was supported by the "Forestry Industry Research Special Funds for Public Welfare Projects (No: 201304502)" and "National Natural Science Foundation of China (No. 31400498)". We give our sincere thanks to Mr. Weigang Zheng in Benxi Maple Leaf Furniture Co., Ltd for his help with the construction of wood drying kilns.

\section{REFERENCES}

Aktas, M.; Sevik, S.; Amini, A.; Khanlari, A. 2016. Analysis of drying of melon in a solar-heat recovery assisted infrared dryer. Solar Energy 137: 500-515.

Ambekar, A.S.; Sivakumar, R.; Anantharaman, N.; Vivekenandan, M. 2016. CFD simulation study of shell and tube heat exchangers with different baffle segment configurations. Applied Thermal Engineering 108: 999-1007.

Ananías, R.A.; Ulloa, J.; Elustondo, D.M.; Salinas, C.; Rebolledo, P.; Fuentes, C. 2012. Energy Consumption in Industrial Drying of Radiata Pine. Drying Technology 30(7): 774-779

Anderson, J.O.; Westerlund, L. 2014. Improved energy efficiency in sawmill drying system. Applied Energy 113: 891-901.

Arsenyeva, O.P.; Cucek, L.; Tovazhnyanskyy, L.L.; Kapustenko, P.O.; Savchenko, Y.A.; Kusakov, S.K.; Matsegora, O.I. 2016. Utilisation of waste heat from exhaust gases of drying process. Frontiers of Chemical Science and Engineering 10(1): 131-138.

Elustondo, D.M.; Oliveira, L. 2009. Model to assess energy consumption in industrial lumber kilns. Maderas-Cienc Tecnol 11(1): 33-46.

Fu, Z.Y.; Zhao, J.Y.; Lv, Y.Y.; Huan, S.Q.; Cai, Y.C. 2016. Stress characteristics and stress reversal mechanism of white birch (Betula platyphylla) disks under different drying conditions. Maderas-Cienc Tecnol 18(2): 361-372.

Gendebien, S.; Bertagnolio, S.; Lemort, V. 2013. Investigation on a ventilation heat recovery exchanger: Modeling and experimental validation in dry and partially wet conditions. Energy and Buildings 62: 176-189.

Gu, L.B. 2007. Recent research and development in wood drying technologies in China. Drying Technology 25(1-3): 463-469.

He, Z.B.; Zhang, Y.; Wang, Z.Y.; Zhao, Z.J.; Yi, S.L. 2016. Reducing wood drying time by application 
of ultrasound pretreatment. Drying Technology 34(10): 1141-1146.

Jokiniemi, T.; Hautala, M.; Oksanen, T.; Ahokas, J. 2016. Parallel plate heat exchanger for heat energy recovery in a farm grain dryer. Drying Technology 34(5): 547-556.

Korkut, S.; Unsal, O.; Kocaefe, D.; Aytin, A.; Gokyar, A. 2013. Evaluation of kiln-drying schedules for wild cherry wood (cerasus avium). Maderas-Cienc Tecnol 15(3): 281-292.

Laurijssen, J.; Gram, F.J.D.; Worrell, E.; Faaij, A. 2010. Optimizing the energy efficiency of conventional multi-cylinder dryers in the paper industry. Energy 35(9): 3738-3750.

Li, X. J.; Zhang, B.G.; Li, W.J. 2008. Microwave-Vacuum Drying of Wood: Model Formulation and Verification. Drying Technology 26(11): 1382-1387.

Minea, V. 2012. Efficient Energy Recovery with Wood Drying Heat Pumps. Drying Technology 30(14): 1630-1643.

O'Connor, D.; Calautit, J.K.S.; Hughes, B. 2016. A review of heat recovery technology for passive ventilation applications. Renewable and Sustainable Energy Reviews 54: 1481-1493.

Ozden, E.; Tari, I. 2010. Shell side CFD analysis of a small shell-and-tube heat exchanger. Energy Conversion and Management 51(5): 1004-1014.

Pazitny, A.; Bohacek, S.; Medo, P.; Balbercak, J. 2015. Application of innovative heat recovery unit in paper industry with potential utilization in wood-processing and furniture industry. Wood Research 60(1): 101-112.

Qiu, Y.; Li, M.; Hassanien, R.H.E.; Wang, Y.F.; Luo, X.; Yu, Q.F. 2016. Performance and operation mode analysis of a heat recovery and thermal storage solar-assisted heat pump drying system. Solar Energy 137: $225-235$.

Simo-Tagne, M.; Zoulalian, A.; Remond, R.; Rogaume, Y.; Bonoma, B. 2017. Modeling and simulation of an industrial indirect solar dryer for iroko wood (Chlorophora excelsa) in a tropical environment. Maderas-Cienc Tecnol 19(1): 95-112.

Tanczuk, M.; Kostowski, W.; Karas, M. 2016. Applying waste heat recovery system in a sewage sludge dryer - A technical and economic optimization. Energy Conversion and Management 125: 121-132.

Tehrani, S.S.M.; Taylor, R.A.; Saberi, P.; Diarce, G. 2016. Design and feasibility of high temperature shell and tube latent heat thermal energy storage system for solar thermal power plants. Renewable Energy 96: $120-136$.

Wallace, J.; Avramidis, S. 2016. Impact of airflow on hem-fir kiln drying. Drying Technology 34(11): 1354-1358.

Yang, X.; Chen, G.Y.; Feng, L.N.; Li, J.R. 2011. Investigation of airflow uniformity at air-exchange device in drying kiln by numerical simulation. Journal of Beijing Forestry University 33(4): 113-117.

Ye, B.; Liu, J.; Xu, X.; Chen, G.; Zheng, J. 2015. A new open absorption heat pump for latent heat recovery from moist gas. Energy Conversion and Management 94: 438-446.

Zadin, V.; Kasemagi, H.; Valdna, V.; Vigonski, S.; Veske, M.; Aabloo, A. 2015. Application of multiphysics and multiscale simulations to optimize industrial wood drying kilns. Applied Mathematics and Computation 267: 465-475.

Zhang, B.G.; Zhou, Y.D.; Ning, W.; Xie, D.B. 2007. Experimental study on energy consumption of combined conventional and dehumidification drying. Drying Technology 25(3): 471-474.

Zhao, J.Y.; Fu, Z.Y.; Jia, X.R.; Cai, Y.C. 2016. Modeling conventional drying of wood: Inclusion of a moving evaporation interface. Drying Technology 34(5): 530-538. 